
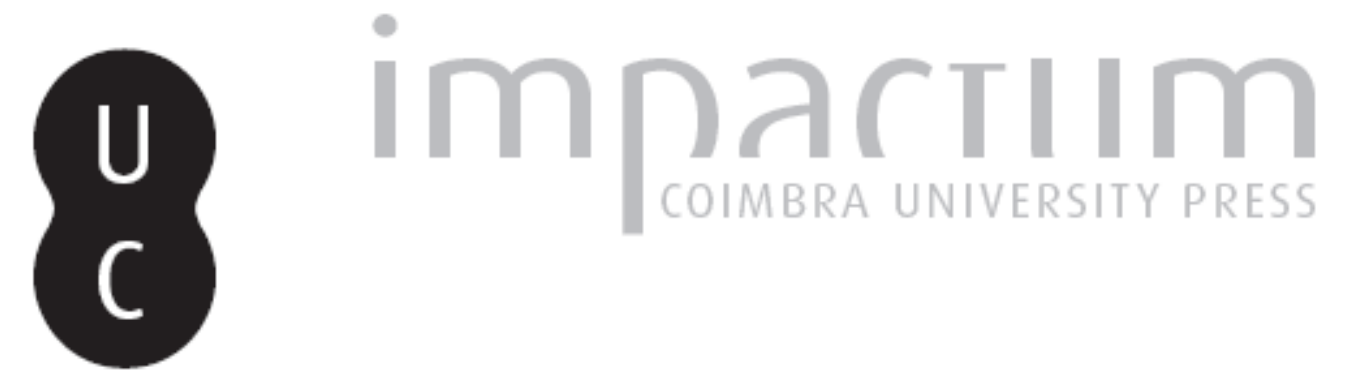

\title{
Planos de igualdade de género nos media: para uma (re)consideração do caso português
}

\author{
Autor(es): $\quad$ Subtil, Filipa; Silveirinha, Maria João \\ Publicado por: Imprensa da Universidade de Coimbra \\ URL \\ persistente: \\ URI:http://hdl.handle.net/10316.2/42811 \\ DOI: \\ DOI:https://doi.org/10.14195/2183-5462_30_3
}

Accessed : $\quad$ 26-Apr-2023 14:40:09

A navegação consulta e descarregamento dos títulos inseridos nas Bibliotecas Digitais UC Digitalis, UC Pombalina e UC Impactum, pressupõem a aceitação plena e sem reservas dos Termos e Condições de Uso destas Bibliotecas Digitais, disponíveis em https://digitalis.uc.pt/pt-pt/termos.

Conforme exposto nos referidos Termos e Condições de Uso, o descarregamento de títulos de acesso restrito requer uma licença válida de autorização devendo o utilizador aceder ao(s) documento(s) a partir de um endereço de IP da instituição detentora da supramencionada licença.

Ao utilizador é apenas permitido o descarregamento para uso pessoal, pelo que o emprego do(s) título(s) descarregado(s) para outro fim, designadamente comercial, carece de autorização do respetivo autor ou editor da obra.

Na medida em que todas as obras da UC Digitalis se encontram protegidas pelo Código do Direito de Autor e Direitos Conexos e demais legislação aplicável, toda a cópia, parcial ou total, deste documento, nos casos em que é legalmente admitida, deverá conter ou fazer-se acompanhar por este aviso.

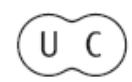


Media Jornalismo Imprensa da Universidade de Coimbra / Coimbra University Press 2 N. 30 Vol. 17, N. . 1 - 2017

\section{MULHERES E MEDIA}




\title{
PLANOS DE IGUALDADE DE GÉNERO NOS MEDIA: PARA UMA (RE)CONSIDERAÇÃO DO CASO PORTUGUÊS
}

\author{
GENDER EQUALITY PLANS IN THE MEDIA: \\ TO A (RE) CONSIDERATION OF THE PORTUGUESE CASE
}

\begin{abstract}
$\overline{\overline{2}}$
FILIPA SUBTIL

Instituto Politécnico de Lisboa. Escola Superior de Comunicação Social, 1549-014 Lisboa, Portugal

fsubtil@escs.ipl.pt
\end{abstract}

MARIA JOÃO SILVEIRINHA

Universidade de Coimbra, Faculdade de Letras, CiC.Digital - Pólo FCSh/nOVA, 3004-530 Coimbra, Portugal mjs@fl.uc.pt

\section{Resumo}

Os Planos Nacionais para a Igualdade são um dos instrumentos de política que os governos nacionais utilizam como expressão dos seus compromissos para com a igualdade de género e outros grupos desfavorecidos rumo à igualdade. Uma análise destes Planos, no caso português, mostra que embora tenha havido ganhos amplamente importantes na sua adoção, uma das suas áreas de preocupação - as mulheres e os meios de comunicação - foi sempre apenas brevemente coberta. No entanto, os Planos são as únicas formas de referência explícita a esta questão nos documentos de política nacional. Concluímos que a política nacional no domínio das mulheres e dos meios de comunicação tem sido incentivada sobretudo por iniciativas europeias sem suficiente ênfase na sua implementação e eficácia.

\section{Palavras-chave}

Planos para a Igualdade e media; género; políticas dos media

\section{Abstract}

National Plans for Equality are one of the policy instruments that national governments use as expressions of commitment to gender quality and other disadvantaged groups towards equality. An analysis of these Plans, in the Portuguese case, shows that although broadly important gains were made during their first adoption, one of their concern areas - women and the media - was always only briefly covered. However, they are the sole forms of explicit reference to this issue in national policy documents.

We conclude that the national policy in the subject of women and the media has been done mostly under the incentive of European initiatives without enough emphasis on their implementation and efficiency.

Equality Plans and the media; gender; media policies 


\section{INTRODUÇÃo}

Desde 1975 que a ONU e o seu organismo especializado nas questões da educação, ciência e cultura, a UNESCO, colocaram como prioridade a promoção da igualdade de género. Com tal objetivo, estas entidades realizaram um conjunto de eventos centrados no problema da discriminação das mulheres e apontaram a necessidade de estas serem consideradas politicamente uma minoria social. Iniciativas como a Década Internacional das Mulheres (1975-1985), que conduziu à instauração do 8 de Março como Dia Internacional da Mulher, e as Conferências Mundiais sobre as Mulheres que tiveram lugar no México (1975), Copenhaga (1980), Nairobi (1985) e Pequim (1995), problematizaram a condição histórica das mulheres e estimularam orientações mundiais favoráveis a políticas conducentes à igualdade de género.

No seio destas políticas nasceu uma preocupação específica com os direitos de comunicação das mulheres e sua relação com os media. Todavia, a afirmaç̧ão desta preocupação em termos políticos desenvolveu-se de modo muito lento e incompleto ${ }^{1}$.

Neste artigo, procuramos estudar e problematizar de que modo estas questões se têm colocado no contexto nacional, focando um dos instrumentos de políticas públicas que tem sido usado: os Planos para a Igualdade, implementados em Portugal desde 1997, e, mais especificamente, o modo como estes têm abordado 0 campo específico das mulheres na comunicação pública.

0 nosso corpus de análise consiste nos cinco primeiros Planos de Igualdade que Portugal teve, sendo igualmente analisados os documentos da sua avaliação publicamente disponíveis que foram produzidos.

Como metodologia, seguimos uma análise crítica destes documentos proposta por Victor Jupp (2006) para quem

A análise crítica (...) envolve uma análise dos pressupostos que sustentam qualquer conta (digamos num documento) e uma consideração sobre quais outros aspetos possíveis são ocultados ou excluídos. Pode também envolver ir além dos próprios documentos para abranger uma análise crítica das estruturas institucionais e sociais em que tais documentos são produzidos. (Jupp, 2006: 232).

Porque entendemos que a documentação disponível de avaliação dos referidos Planos já contém muitas das análises sobre o modo como os problemas são definidos, as explicações dadas e as ausências de soluções identificadas, assumimos que uma parte do nosso trabalho terá uma componente forçosamente descritiva. Ainda assim, procuramos resumir e descrever a produção documental neste campo a partir de um quadro teórico que permite uma compreensão crítica das questões em análise.

2. As orientações políticas sobre "as mulheres e os media", os Planos para Igualdade E A TRANSFERÊNCIA DE POLÍTICAS

Foi no contexto referido que o tópico das mulheres nos media e o papel destes como "recurso específico de opressão" (Gallagher, 2006: 11) adquiriu relevância

1 Para uma revisão detalhada da cronologia das políticas sobre o tópico das Mulheres e dos Media a nível europeu, ver Byerly e Padovani (2017). 
crescente (Gallagher, 2011)2. As universidades europeias e norte-americanas começaram a revelar interesse pelos estudos feministas voltados para o papel dos media na construção das identidades e no discurso público sobre as desigualdades entre homens e mulheres ${ }^{3}$. No entanto, foi a Declaração e a Plataforma de Ação da Conferência de Pequim, resultado das discussões ocorridas na IV Conferência Mundial sobre as Mulheres de 1995, que colocou os media, pela primeira vez, entre as áreas críticas de preocupação para com as mulheres. Os media foram nesse documento descritos como cruciais na perpetuação das relações de desigualdade entre géneros em todos os sectores da sociedade. Sob o título "As mulheres e os media" ${ }^{4}$, identificam-se dois objetivos estratégicos: "incrementar a participação e 0 acesso das mulheres à expressão das suas ideias e à tomada de decisão nos meios de comunicação social e nas novas tecnologias da comunicação"; e "fomentar uma imagem equilibrada e não estereotipada das mulheres". Estas intenções deveriam fomentar ações concretas e concertadas assumidas pelos governos, sistemas de media nacionais e internacionais, organizações de publicidade, entidades não-governamentais e associações profissionais dos media.

Esses esforços no sentido de produzir mensagens mais equilibradas e inclusivas de género nos media e na comunicação de massas também devem ser colocados no âmbito de outras políticas, especialmente aquelas que lidam especificamente com os media como instituições.

Por sua vez, essas políticas dos media podem ser criticamente relacionadas com contextos ideológicos mais amplos que enquadram a forma como os governos e as empresas dos media moldaram a elaboração de regras sobre propriedade, conteúdo e operações mediáticas, como um todo (Silveirinha, 2012).

A este respeito, Katharine Sarikakis lembra-nos que, ao longo da história das políticas de comunicação social da UE, as numerosas tentativas de regulamentar os media têm encontrado uma forte resistência por parte do sector privado - trata-se da abordagem de laissez-faire da Comissão (Sarikakis, 2004; a este respeito, ver também Freedman, 2008; 2010). Isto significou que as questões de interesse público seriam sistematicamente subsumidas pelas prioridades económicas da indústria dos media. Nesse contexto, "0 trabalho da Comissão relativo à igualdade

2 Veja-se, em 1980, o relatório da UNESCO, Women and Media. É também neste ano que é criado o Programa Internacional para o Desenvolvimento da Comunicação (PIDC), iniciativa que, desde a sua fundação, tem financiado vários projetos propostos pelos estados-membros que privilegiam as mulheres para que elas alcancem lugares de destaque nos media (Cerqueira 2008). Ainda no mesmo ano é publicado, também pela UNESCO, Many Voices. One World (também conhecido como o "MacBride Report"), relatório redigido pela Internacional Commission for the Study of Communication Problems (na parte III, dedicada aos Problems and Issues of Common concern, no capítulo IV sobre "Images of the World" existe um subponto dedicado aos "Equal rights for women". Em 1990, a UNESCO cria o Sector da Comunicação e Informação (CI), cujos programas se inspiram na Constituição da UNESCO. Esta entidade deve promover o "free flow by word and image". Os principais objectivos estratégicos do Cl são: "promoting the free flow of ideas and universal access to information"; "promoting the expression of pluralism and cultural diversity in the media and world information networks"; "promoting access for all to ICT's".

3 Como assinalam Cerqueira e Cabecinhas, as análises ao papel dos atores políticos a nível internacional neste domínio não são consensuais (2012: 107-108).

4 Secção J da citada Declaração de Pequim. 
entre os géneros no conteúdo dos meios de media seria de natureza 'suave', referindo-se à contribuição - e não à obrigação - dos meios de comunicação de uma representação não sexista" (Sarikakis e Nguyen, 2009: 208). Muitas vezes, a questão do sexismo no conteúdo e na representação dos media é confundida com debates sobre pornografia e, portanto, enquadrada como questões de censura. Contra evidências óbvias, a indústria afirma que a autorregulação é suficiente para equilibrar representações e conteúdo. Além disso, o sector dos meios de comunicação tem resistido fortemente a quaisquer políticas de integração da perspetiva do género.

Tendo em conta todas estas tendências, as políticas sobre as mulheres e os media devem ser estudadas como parte das questões mais amplas em torno da política dos meios de comunicação. Tais questões, em resumo, caracterizam-se "por relações complexas e antagónicas entre o mercado e os objetivos políticos: cada processo de mudança fundamental num quadro político é conduzido através de mudanças normativas e retóricas que cimentam os desenvolvimentos de facto". (Sarikakis e Ganter, 2014: 18). Ora, é precisamente a construção dessas mudanças em documentos de política - os Planos de Igualdade - e nos documentos associados que nos propomos explorar.

Antes de o fazermos, porém, deveremos ainda ter em conta alguns conceitos que ajudam a explicar 0 aparecimento e as dinâmicas de implementação destes planos. Nesse sentido, e referindo-se à globalização das políticas de igualdade, Virginia Ferreira identificou a "aceleração e intensificação da interferência dos organismos internacionais nas políticas de igualdade" (2000: 19). Ligando esses processos à dinâmica do reformismo de Estado, à existência de feminismos intraestatais e estatais e à ação das ONGs, Ferreira mostra como a agenda de igualdade entre homens e mulheres se estabeleceu nos Estados-nação como resultado da pressão de compromisso sobre os governos, transformando as entidades nacionais em "câmaras de eco" para as questões de política internacional (Ferreira 2000; Ferreira e Monteiro, 2013). Como resultado dessa crescente influência dos organismos internacionais e de uma combinação de sensibilidades feministas intraestatais e estatais do Estado, a igualdade de género tornar-se-ia um objetivo amplamente aceite na administração pública portuguesa. Um dos seus instrumentos visíveis são os Planos para a lgualdade. Estes são parte do mecanismo institucional nacional para promover a igualdade e podem ser definidos como "um conjunto de iniciativas a serem seguidas horizontalmente pelos diferentes departamentos e instituições governamentais" (Bustelo e Peterson 2005: 2).

Nesse sentido, a adoção destes planos para a igualdade pelos decisores políticos nacionais não deve ser apenas interpretada como formas de fazer face aos problemas locais, mas como resultado de uma política internacional mais alargada e da dinâmica dos processos de transferência de políticas que tornou cada vez mais difícil ignorar determinadas áreas de preocupação nas políticas internacionais.

No contexto mais vasto da produção de políticas em que Portugal se insere, também o conceito de europeização, entendido amplamente como o processo de adaptação interna às pressões que emanam direta ou indiretamente da adesão à EU como 0 impacto das políticas europeias nos diferentes territórios europeus (Magone, 2006), poderá ajudar-nos a compreender a adoção portuguesa das políticas de igualdade. Nesse campo específico, Emanuela Lombardo e Maxime Forest (2012: 214) insistem que "Uma melhor análise das políticas de igualdade de oportunidades e de género exige a adoção de abordagens abrangentes e pluralistas da euro- 
peização". Estas autoras contribuíram de forma decisiva para a contextualização e análise das políticas europeias de género através de uma abordagem discursiva e sociológica à Europeização centrada na articulação dos significados da igualdade de género e das suas mudanças pela ação política e discursiva de uma série de atores institucionais e da sociedade civil. Com efeito, o processo só poderá ser devidamente compreendido se tivermos em conta diferentes níveis de análise (diferentes atores e seus discursos, heranças institucionais, mecanismos de aprendizagem e seus efeitos) e os múltiplos níveis de produção de políticas na União Europeia.

No caso que aqui nos ocupa, consideramos pertinente ter em conta, por fim, o conceito de "transferência de políticas" para melhor elucidar os problemas levantados pelos aspetos práticos de implementar, ao nível nacional, políticas inspiradas por regulação internacional. Na verdade, a "transferência de políticas" é, como reconhecem Katharine Sarikakis e Sarah Ganter (2014), um novo conceito para os estudos dos media da comunicação. No seu trabalho, as autoras percorrem os detalhes das transformações de políticas dos media no MERCOSUL e mostram a relevância da análise de processos de políticas multinacionais e multiníveis para entender como estas políticas são moldadas e transferidas em torno de interesses chave e por vezes oposicionais.

David Dolowitz e David Marsh (1996: 344) definem a transferência de políticas como "um processo no qual o conhecimento sobre políticas, arranjos administrativos, instituições etc. num dado tempo e/ou lugar é usado no desenvolvimento de políticas, arranjos administrativos e instituições noutro momento e/ou lugar. Em termos semelhantes, Mark Evans (2009: 243-244) define a transferência de políticas como um "processo ou um conjunto de processos em que o conhecimento sobre instituições, políticas ou sistemas de implementação num setor ou nível de governança é usado no desenvolvimento de instituições, políticas e sistemas de implementação noutro setor ou nível de governação". Nessa visão, o conhecimento transferido pode estar relacionado com objetivos políticos, conteúdo de políticas, instrumentos de política ou mecanismos administrativos.

Vários atores podem estar envolvidos no processo de transferência de políticas, tanto em termos de implementar quanto de impulsionar novas medidas. Diane Stone (2004) destacou o papel desempenhado pelos atores não-estatais que atuam como "empreendedores de políticas" e interagem com funcionários do governo e organizações internacionais na disseminação internacional de ideias e informações. Do mesmo modo, a literatura feminista sobre políticas de igualdade de género reafirmou o papel das ONGs, bem como das instituições feministas intraestatais e estatais (Mazur, 2005; Monteiro e Ferreira, 2012).

Em termos processuais, os mecanismos de transferência de políticas variam, como varia a sua eficácia. David Marsh e Jason C. Sharman identificaram o mimetismo como um desses mecanismos - os outros três são a aprendizagem, a competição e a coerção -, descrevendo o processo de copiar simbolicamente uma iniciativa estrangeira (Marsh e Sharman, 2009). 0 "mimetismo" é um mecanismo caracterizado pela falta de preocupação técnica ou racional com a eficiência funcional, isto é, a ausência de uma busca de eficácia. Ao usá-lo, "um governo pode saber muito bem que a política em questão é tecnicamente ineficaz, mas atribui maior valor aos benefícios sociais entre públicos nacionais e estrangeiros" (Marsh e Sharman, 2009: 272).Embora 0 conceito tenha principalmente como objetivo explicar a mudança de política e apesar 
de, ao falar de planos de igualdade, estarmos a falar de soft policy-making, acreditamos que ele também pode ajudar-nos a explicar situações na formulação de políticas como as encontradas nos Planos Nacionais para a lgualdade, como abaixo veremos.

\section{A adopção de políticas públicas de promoção da igualdade de género em Portugal}

Em Portugal, só se pode falar verdadeiramente de uma estratégia política concertada de promoção da igualdade de género consonante com as que foram promovidas pela ONU e a sua agência UNESCO, quaisquer que tenham sido as suas limitações, após duas décadas do seu início ${ }^{5}$ internacional. No entanto, importa mencionar que, apesar da promoção da igualdade de género não ter sido uma prioridade nacional, existiram várias iniciativas, entre os anos de 1970 e 1995, coincidentes em larga medida como o processo de democratização da sociedade portuguesa. Entidades como o Grupo de Trabalho para a Definição de uma Política Nacional Global acerca da Mulher (1970), o Grupo de Trabalho para a Participação da Mulher na Vida Económica e Social (1971) e da Comissão da Condição Feminina (CCF) $(1975)^{6}$, bem como outros actores da sociedade civil, como os partidos políticos, as associações e movimentos de mulheres, envolveram-se activamente, discutindo e redigindo documentos sobre o tema (Monteiro e Portugal 2013; Monteiro 2011)7.

Foi apenas em 1997 que o programa do XIII Governo Constitucional, dirigido pelo então Primeiro-Ministro António Guterres, assumiu o compromisso com a execução das políticas públicas no âmbito da cidadania e da promoção da igualdade ${ }^{8}$. 0 tema surge enunciado no documento das grandes opções do plano para 1997 (Lei n $52-$ B/96), meses antes do lançamento do I Plano Nacional para a Igualdade de Oportunidades (1997-1999) (RCM, nº 49/1997). Nestes documentos é afirmado o compromisso do governo português com as instâncias internacionais e europeias (ONU, EU, CPLP, entre outras) relativamente à imprescindibilidade de pôr em prática estratégias de mainstreaming de género nos vários sectores da sociedade portuguesa.

Aquele I Plano Nacional foi o ponto de partida para os que vieram na sua sequência e que prosseguem até ao presente. Seguiu-se o II Plano Nacional para a Igualdade para o triénio 2003-2006 (RCM, n 184/2003), depois o III Plano Nacional

5 As políticas para a igualdade de género tiveram de forma tímida e avulsa o seu início com a instauração da República, em 1910, tendo sido suspensas durante o Estado Novo e retomadas com 0 25 de Abril de 1974. Para esta retoma foi decisiva a instauração do princípio da igualdade na Constituição de 1976 (Rêgo 2012).

6 Em 1975, a então Ministra dos Assuntos Sociais, Maria de Lourdes Pintasilgo, e presidente do Grupo de Trabalho, colocou a Comissão em instalação, designando-a de Comissão da Condição Feminina. Viria a ser instituída pelo Decreto-Lei nº 485/77, de 17 Novembro (Monteiro e Ferreira, 2012: 16; Silva, s.d.).

7 A nível internacional, refira-se que Portugal foi, em 1980, um dos primeiros países a ratificar a Convenção das Nações Unidas para a Eliminação de todas as Formas de Discriminação contra as Mulheres.

8 Note-se, no entanto, que, em 1994, o governo do Partido Social Democrata, liderado por Aníbal Cavaco Silva, produziu uma Resolução do Conselho de Ministros (RCM 32/94, de 17 de Maio) que pode ser entendida como uma primeira manifestação no sentido do reconhecimento das políticas de mainstraming e que foi por muitos interpretada como uma tentativa de dar um sinal à comunidade internacional que Portugal estava atento à preparação da sua participação na Conferência de Pequim (Monteiro, Portugal, 2013). 
para a Igualdade - Cidadania e Género, entre 2007-2010 (RCM, nº 82/2007) e, finalmente, o IV Plano Nacional para a Igualdade - Género, Cidadania e Não Discriminação para o período 2011-2013 (RCM, $n^{0}$ 5/2001). No presente ano, conclui-se a implementação do V Plano Nacional para a Igualdade: Cidadania, Género e Não Discriminação (RCM, no 103/2013).

\section{Plano Global para a Igualdade de Oportunidades (1997-1999)}

Dando início à análise crítica dos Planos relativamente à igualdade de género nos media, deve salientar-se que a elaboração e concretização do I Plano ${ }^{9}$ de operacionalização e implementação foi um processo moroso e atribulado. (cf. Monteiro e Portugal 2013). 0 Plano é apresentado nove anos após a Comissão da Condição Feminina e a secção de Organizações Não-Governamentais do seu Conselho Consultivo terem recomendado às instâncias com responsabilidades políticas uma Plataforma Comum de Acção, um plano de integração da questão de género nos vários domínios da vida pública (cf. Monteiro 2011).

Na nota introdutória, o I Plano assume que apesar de a igualdade de tratamento entre mulheres e homens ser um princípio fundamental do direito português e comunitário, este facto não foi até então suficiente para a sua efetiva concretização. Consciente das mudanças ocorridas nas relações sociais de género que tinham ocorrido em Portugal, resultantes da participação crescente das mulheres no sistema de emprego e da independência económica por ele proporcionado, assim como 0 aumento da escolaridade, o legislador reconhece que tal não se tinha traduzido numa "melhoria global do estatuto social das mulheres nem o usufruto de uma cidadania plena" (p. 1323). É por esse motivo, ao qual se associaram os compromissos assumidos pelos países signatários da Plataforma de Acão da IV Conferência Mundial das Nações Unidas sobre as mulheres (como era o caso de Portugal) e pelo carácter prioritário destas políticas, aceite internacionalmente, que o XIII Governo considerou imperativo a aprovação do plano global para a igualdade de oportunidades. Foi admitido que esta orientação era fundamental para um "desenvolvimento económico sustentado", para o "alargamento da cidadania" e para "0 aprofundamento da democracia" (idem). 0 plano é um documento genérico, dividido entre medidas de carácter global e sectorial. Sendo praticamente omisso quanto ao papel dos media na promoção da igualdade de género, uma análise mais esmiuçada permite detetar um conjunto de intenções neste domínio. Estes propósitos são transversais a vários sectores da sociedade portuguesa e acabam por afetar direta ou indiretamente os estudantes e profissionais dos meios de comunicação social ${ }^{10}$.

Em rigor, a referência direta aos media surge apenas uma única vez. Estes são apresentados como meio para atingir um determinado fim - a sensibilização da opinião pública no que concerne à mudança de mentalidades quanto ao papel da mulher na sociedade. Em nenhum momento, os media são equacionados como veículos de produção e reprodução de estereótipos de género, quer dizer, como parte dos problemas da desigualdade e opressão das mulheres.

9 RCM n 49/97, DR, I série B, nº 70, 24-03-1997.

10 Nas medidas de carácter global, destaca-se o objetivo 1 nos seus pontos 3 e 7 e nas medidas de carácter sectorial o objetivo 2, na medida preventiva 1, e 7 nos seus pontos 2 (p. 1324). 


\section{Plano Nacional para a Igualdade (2003-2006)}

Sete anos após da Plataforma de Ação de Pequim, o II Plano Nacional para a Igualdade ${ }^{11}$ incorporou, pela primeira vez, os media enquanto área de intervenção. Na linha de orientação da Declaração de Pequim, o enquadramento do Plano começa por afirmar que a promoção da igualdade de oportunidades entre as mulheres e os homens, "a todos os níveis e em todas as áreas" é uma prioridade do XV Governo Constitucional. Todavia, quando enuncia as áreas que foram assumidas como prioritárias, os media não surgem referenciados, apesar de serem - como já se disse tidos por aquela entidade internacional uma das doze áreas críticas de preocupação.

É já no interior do articulado do Plano, sob o título "Educação, formação e informação", que surge uma secção dedicada à "comunicação social"12. 0 legislador reconhece que os media têm a responsabilidade da transmissão de informação junto da opinião pública e, por isso, desempenham um papel relevante na formação da consciência da cidadania; e que a reprodução e a perpetuação de estereótipos de papéis sociais de homens e mulheres na informação que veiculam ignoram o papel desempenhado pelas mulheres nas diversas esferas da vida social. No sentido de alterar esta situação, confere-se aos media o papel de "passar uma mensagem actual das questões da igualdade entre mulheres e homens..." (p. 8027).

Para responder às necessidades identificadas, são propostas duas medidas para os meios de comunicação. Em primeiro lugar, apela-se à "sensibilização das direções dos órgãos de comunicação social e dos jornalistas para a importância da igualdade de género", cabendo à Comissão para a Igualdade e para os Direitos das Mulheres (CIDM) ${ }^{13}$ e à Comissão para a Igualdade no Trabalho e no Emprego (CITE) $)^{14}$ promover um conjunto de ações que conduzam à concretização dos objetivos propostos neste domínio. Entre as iniciativas avançadas, destaca-se 0 contacto com os principais meios, mantendo-os informados da atualidade nacional e internacional, a elaboração e disseminação de guias de boas práticas que enunciem os princípios a seguir neste âmbito, ações de formação para jornalistas, a celebração de protocolos com os meios para a inclusão de trabalhos de investigação sobre a temática da igualdade e no incentivo à criação de prémios ${ }^{15}$ nos domínios da publicidade e da reportagem que promovam a igualdade de género. Em segundo lugar, aponta-se para a necessidade de alertar os responsáveis pelo mecanismo regulador da comunicação social no sentido de garantir a conformidade das imagens de mulheres e homens veiculadas pelos media com os direitos fundamentais e o princípio da igualdade.

Concluído o período de implementação, este II Plano Nacional foi objeto de uma avaliação externa, coordenada pela socióloga Virgínia Ferreira (Ferreira et. al., 2007). Embora identifique indícios de estratégias conducentes aos objetivos propostos, como o protocolo estabelecido com a RTP, a criação e implementação

11 RCM, n $n^{0} 184$, DR, I série B, nº 273, 23 Novembro 2003.

12 Ver medida 2, ponto 5.

13 Criado pelo DL n 166/91 de 9 de Maio.

14 Criado pelo DL n $392 / 79$ de 20 de Setembro

150 Prémio Paridade: Mulheres e Homens na Comunicação Social foi instituído pela CIG, em 2005, no âmbito do II Plano Nacional. 
de prémios, o relatório de avaliação destaca a baixa concretização das medidas nesta área de intervenção:

Quer os indicadores de realização, quer os indicadores de impacto que analisámos mostram como esta área se mantém como crítica e longe do objetivo definido, no sentido de encontrar formas que permitam "fazer passar uma mensagem catual das questões da igualdade entre mulheres e homens através dos órgãos de comunicação social. (Ferreira et. al.., 2007: 49)

Esta situação decorreria da ausência de uma estratégia de profissionalização da CIDM como fonte jornalística; de as medidas propostas terem sido sobretudo orientadas para o sector do jornalismo, deixando de fora outros profissionais da comunicação; da ausência de medidas que visassem especificamente questões de paridade no domínio da comunicação; e da falta de instrumentos específicos para a concretização das medidas de sensibilização e formação, como elaboração de estratégias, planos de formação, definição de instrumentos de planeamento, realização e de avaliação (Ferreira et al., 2007: 49-52). Finalmente, a avaliação recomenda a necessidade de preparar medidas mais vastas, concertadas e avaliadas de publicitação das questões da igualdade:

éo cruzamento das várias vertentes do problema da igualdade no espaço público que o torna especialmente complexo, obrigando a que se foquem várias dimensões. Estas, no entanto, têm de passar por estratégias mais profissionalizadas de comunicação publicitária, institucional e de agendamento das questões (Ferreira et al., 2007: 52).

III Plano Nacional para a Igualdade - Cidadania e Género (2007-2010)

Para o triénio 2017-2010 entrou em vigor o III Plano ${ }^{16}$ que prosseguiu, em linhas gerais, 0 anterior, tentando, contudo, ultrapassar algumas das fragilidades assinaladas no relatório de avaliação citado anteriormente. Logo no enquadramento, refere-se a importância de prosseguir um esforço combinado de combate aos estereótipos de género em todos os domínios da vida pública, em especial, na educação e formação, saúde, mercado de trabalho, desporto, cultura e comunicação social. 0 sector dos media surge enquadrado na área de intervenção "Cidadania e Género", no âmbito do problema dos estereótipos ${ }^{17}$. Referem-se os estereótipos ligados à representação política, à participação cívica, à linguagem tida como "fundamental na construção das identidades e na reprodução das representações sociais de género" (p. 3959) e à comunicação social e seus agentes. Estes,

pelo impacto da sua influência, podem ser agentes indiretos de mudança e de promoção de uma cultura baseada na Igualdade de Género, tal como recomendado em vários documentos comunitários sobre esta matéria que alertam para o seu papel na manutenção de estereótipos geradores de limitações à liberdade, quer de mulheres, quer de homens, nas várias dimensões e papéis ao longo da vida. (p. 3959).

16 DR, $1^{\text {a }}$ série, nº 119, 22 Junho 2007: 3950-3987.

17 Área da intervenção 3, na subárea "Estereótipos". 
sensibilizar a comunicação social para o seu papel de desconstrução dos estereótipos de género, para a valorização da participação cívica como fator de crescimento individual e coletivo e, consequentemente, para a sua responsabilidade na promoção de uma cidadania ativa e igualitária. (p. 3959)

Seguindo a orientação do plano anterior, volta a reconhecer-se o papel fundamental da Entidade Reguladora para a Comunicação Social (ERC), na missão de garante do respeito pelos direitos, liberdades e garantias dos cidadãos e cidadãs. A linguagem e a comunicação social surgem como alvo de dois objectivos operacionais. Propõe-se a promoção da "igualdade de Género na Linguagem", o que significa estabelecer "parcerias com instituições na área da linguística para promover formas de utilização da gramática portuguesa, a atualização dos conceitos de homem e mulher e identificar possibilidades de uma nova gramática inclusiva do género" (p. 3959). Especificamente em relação aos media, assume-se a orientação de "sensibilizar para a igualdade de género" e de ser da sua responsabilidade contribuir para a alteração dos estereótipos e para a promoção da cidadania". 0 sector da comunicação aparece ainda no contexto das medidas de acção ${ }^{18}$. A orientação é prosseguir com as ações de sensibilização para os direitos humanos e a igualdade de género, quer junto dos profissionais dos media e da publicidade, quer nos futuros profissionais, incluindo estas temáticas na formação académica e profissional destas áreas, quer ainda no incentivo e promoção de boas práticas através da manutenção do Prémio Paridade. Despontam também novas áreas de intervenção que passam a incluir outros protagonistas: promoção da investigação sobre estereótipos e desigualdade nos media e na publicidade; aplicação das orientações da Comunidade Europeia relativas a imagens dignas de homens e mulheres; a monitorização da aplicação do código da publicidade; e a necessidade de capacitar crianças e jovens para uma leitura crítica dos media.

Este Plano foi igualmente avaliado por uma comissão externa de peritos, novamente coordenada por Ferreira. As conclusões mostram que, entre as medidas de ação propostas, apenas uma foi executada - a que dizia respeito ao Prémio Paridade: Mulheres e Homens na Comunicação Social. As medidas ligadas à consciencialização dos profissionais dos media e da publicidade para a promoção da igualdade, à capacitação de crianças e jovens para uma leitura crítica dos media e à sensibilização para os direitos humanos e igualdade de género na formação do jornalismo, comunicação e marketing só foram consideradas parcialmente executadas. Foi indicado não haver informação disponível para as medidas relativas à promoção do estudo sobre os estereótipos e desigualdades nos media e na publicidade, à aplicação das orientações da Comissão Europeia relativas às imagens dignas de homens e mulheres e à monitorização da aplicação do código da publicidade.

A avaliação só poderia assim concluir que o III Plano ficou aquém da sua plena concretização. É ainda destacada a confusão conceptual resultante da junção das

18 Em concreto, das treze medidas de ação, sete estão diretamente orientadas para o sector da comunicação (da alínea G à M) - jornalismo, publicidade e marketing. 
preocupações com a tomada de decisão e com as imagens de sentido, identificado logo no início do capítulo "Cidadania e Género". Menciona-se que o número de informações vagas ou indisponíveis terá dificultado também a definição de um quadro preciso e eficaz nesta área de atuação. Ainda assim, são destacadas como positivas as parcerias (com o Centro Protocolar de Formação para Jornalistas - CENJOR), a maior sensibilidade no interior do Comissão para a Cidadania e Igualdade de Género (CIG) $)^{19}$ para a importância do contacto com a comunicação social e a atenção que começou a ser prestada aos campos de produção de sentido, mesmo que surjam de forma pontual e desorganizada. É o caso da ênfase que é dada à urgência de uma linguagem inclusiva e à monitorização do código da publicidade.

\section{Plano Nacional para a Igualdade - Género, Cidadania e Não Discriminação (2011-2013)}

No IV Plano ${ }^{20}$, 0 último para o qual se dispõe de Relatório de Avaliação Final, destaca-se o regresso de uma área estratégica dedicada aos "Media, Publicidade e Marketing"21. No enquadramento geral reafirma-se, de forma mais enfática do que nos anteriores, que o Plano se enquadra nos compromissos assumidos por Portugal nas várias instâncias internacionais e europeias com destaque para a ONU, o Conselho da Europa e a União Europeia. Num contexto de profunda crise económica e financeira a nível nacional e internacional, o IV Plano adopta uma noção de igualdade remetida para o "fator de competitividade" a partir do que designa de uma tripla abordagem: reforço da transversalização da dimensão de género e do mainstreaming de género para a construção de uma cidadania plena nos domínios público e privado; a conjugação desta estratégia com ações específicas, incluindo ações positivas, destinadas a ultrapassar as desigualdades que afetam as mulheres em particular; e, por último, a introdução da perspetiva de género em todas as áreas de discriminação, prestando particular atenção aos diferentes impactos desta junto de homens e mulheres" (p. 300).

A introdução à área dos "Media, Publicidade e Marketing" chama a atenção para a importância da representação de homens e mulheres nos media e o como ela é fulcral para a edificação de um "mundo mais paritário", algo há muito assumido na agenda de reflexão académica feminista dos media. 0 articulado assume que os discursos dos media, os produtos culturais, as audiências, as instituições mediáticas e a própria sociedade estão atravessadas por "definições e visões do mundo de diferentes grupos etários, étnicos, de classe, de cultura e de sexo" que contribuem para a construção e reconstrução das identidades. Também as categorias de feminilidade e masculinidade são consideradas como não sendo estáticas, e que essa fluidez pode também advir, entre outras condições, das próprias mutações ao longo do tempo das representações dos media. Sugere-se que as mensagens mediáticas veiculadas no âmbito dos conteúdos informativos, do entretenimento ou da publicidade, "deve[re]m obedecer a princípios de legitimidade cívica, deontoló-

19 Decreto-lei n 164/2007, 3 Maio, sucede nas atribuições à Comissão para a Igualdade e os Direitos das Mulheres e da Estrutura de Missão contra a Violência Doméstica.

20 RCM n5/2011, DR, $1^{\text {a }}$ série $-n^{0} 12,18$ Janeiro 2011: 296-321.

21 Área 8. 
gica e ética, seguindo as orientações políticas e jurídicas da Entidade Reguladora para a Comunicação (ERC)"22.

A circunstância de os media procurarem objetivos comerciais é considerada não ser um impedimento para a falta de respeito dos princípios éticos e estéticos favoráveis à promoção de uma sociedade inclusiva. Veja-se o seguinte excerto:

Assim, é indispensável sensibilizar a comunicação social para o papel que deverá ter na desconstrução de estereótipos de género, na valorização da participação cívica como facto de crescimento individual e coletivo e, consequentemente, na responsabilidade de promoção de uma cidadania plena e global, das quais se destaca a promoção da formação em igualdade de género para profissionais da comunicação social e publicidade, a divulgação de trabalhos de publicidade e reportagem que defendam o respeito pelos direitos humanos e da igualdade de género na formação em jornalismo e comunicação. (p. 312)

Aos media cabe facilitar a promoção de imagens equilibradas e diversificadas de homens e mulheres; estimular a uma maior participação de mulheres na produção e tomada de decisão; produzir e divulgar materiais sobre mulheres em posições de liderança; disseminar informações que aumentem a consciência do público sobre os direitos humanos das mulheres; fomentar a emergência de especialistas na área do género com aptidões para elaborar análises sociais, económicas, culturais e políticas que incluam a perspetiva de género ${ }^{23}$. Comparativamente com o III Plano, as medidas propostas não incluem uma parte significativa das recomendações do Relatório de avaliação do referido plano. Permanece a mesma orientação geral: "sensibilização" é o termo que mais se repete, seja através de formação dos profissionais dos media, seja através da atribuição de prémios de produção jornalística ou acrescentando distinções às empresas de marketing e publicidade que promovam conteúdos não discriminatórios.

Em contraste com a avaliação do plano anterior, o Relatório de Avaliação do IV Plano, coordenado pela também socióloga Anália Torres, considera que a maioria das medidas foram executadas, destacando-se a formação dirigida aos profissionais dos media, as acções de igualdade de género e de violência de género ${ }^{24}$ (Torres et al., 2013). As críticas assinaladas durante a sessão de trabalho que preparou o relatório apontam uma vez mais para as medidas se circunscreverem ao jornalismo e à publicidade, descurando outros domínios de intervenção num campo dos media que é cada vez mais complexo e alargado. Observa-se criticamente o modo como os estereótipos são abordados pelos media em geral, chamando-se a atenção para

22 Acrescenta-se ainda que a ERC é "estatutariamente obrigada a fazer garantir o respeito pelos direitos liberdades e garantias de cidadãos e cidadãs" (alínea d) do artigo $8^{\circ}$ dos Estatutos da ERC, publicados em anexo à Lei $n^{0} 53 / 2005$, de 8 de Novembro.

23 Esta área estratégica tem, pois como objectivo primordial "promover medidas específicas para a integração da perspectiva de género na área dos media" e integra três medidas de acção.

24 Entre as medidas executadas, destaca-se a dedicada à área da formação e sensibilização dirigidas a profissionais dos media, onde foram aprovados um número de projectos significativo (142), 48 dos quais desenvolvidos por organizações da sociedade civil. Da lista constam ainda outros elementos. 
o facto de serem "...descuradas questões mais subliminares, devendo existir maior detalhe às mesmas ...". Refere-se ainda a ausência de uma visão estratégica que inclua as áreas da educação, da juventude e dos media, a inexistência de plataformas de comunicação, parcerias ou trabalho em rede. ${ }^{25}$

\section{Plano Nacional para a Igualdade: Cidadania, Género e Não Discriminação (2014-2017)}

Em 2014 teve início o V Plano, encontrando-se em fase final de implementação. Tal como os II e IV Planos, contempla uma área estratégica dedicada à "Comunicação social". Na sua Introdução é reafirmado o dever das entidades públicas prosseguirem políticas de igualdade de género, devendo estar presente em todos os aspetos da tomada de decisão pública e política. Em linha com os planos anteriores, o documento volta a assumir que Estado Português está empenhado na reprodução das políticas internacionais neste domínio. A preocupação com os domínios da linguagem e como esta pode reproduzir representações sociais de género predominantes num determinado contexto histórico e cultural, que tinha sido ponderada no III Plano, é igualmente reiterada na introdução. Para enfrentar este problema sustenta-se que a Administração Pública deve ser pioneira na adoção de "uma linguagem escrita e visual que dê igual estatuto e visibilidade às mulheres e aos homens nos documentos produzidos, editados e distribuídos" (p. 7037).

0 articulado da área estratégica relativa à "Comunicação social" 26 insiste no lugar central que os meios de comunicação ocupam nas sociedades contemporâneas e retoma que os meios de comunicação persistem em veicular mensagens e imagens estereotipadas do ponto de vista das relações e papéis de género. No sentido de alterar esta situação, realça-se que os media podem contribuir para dar visibilidade a um conjunto de realidades relacionadas com a desigualdade de género, cumprindo assim uma importante missão social e contribuindo para uma sociedade mais igualitária. Para alcançar tais objetivos, são propostas quatro medidas que decorrem dos seguintes objetivos a serem implementados pela Presidência do Conselho de Ministros e pela Comissão para a Igualdade de Género:

Capacitar os(as) profissionais de comunicação, em particular jornalistas, para a introdução da dimensão de género nos conteúdos por si produzidos ou editados; criar mecanismos de sinalização de conteúdos jornalísticos e publicitários sexistas e estereotipados do ponto de vista do género; [e] promover a sensibilização do público em geral sobre as questões da igualdade de género e não discriminação, com recurso ao meio de comunicação privilegiado, que é a televisão. (p. 7047)

De referir que antes da sua aprovação em Conselho de Ministros, o documento foi objeto de consulta pública. No âmbito do sector da comunicação social, pronunciaram-se a $\mathrm{ERC}^{27}$ e académicos que investigam neste domínio.

25 A ERC terá participado na avaliação do IV Plano, numa reunião coordenada pelo Centro Interdisciplinar de Género (ISCSP, UTL), em que estiveram presentes outros parceiros. 0 relatório desta avaliação nunca foi tornado público.

26 Área estratégica 6.

27 Deliberação 259/2013, 5 Outubro. 
As medidas propostas continuam a remeter para o mesmo tipo de orientações de sensibilização dos jornalistas e do público sobre as questões da igualdade de género, assim como para a monitorização de conteúdos mediáticos sexistas e estereotipados. Sendo um plano que entrou em vigor num período de profundas mutações no universo dos media, o documento não presta atenção aos efeitos de tal mudança no que respeita às novas formas de produção, distribuição e consumo dos media e seus conteúdos. Num contexto em que a informação pública não é já totalmente produzida nem difundida através da mediação jornalística e em que com frequência não há uma filtragem rigorosa das fontes e das notícias, é insuficiente centrar a acção contra a discriminação nos jornalistas e nos géneros jornalísticos. Haveria decerto que incentivar uma cultura de informação que fosse não só mais além da definição tradicional das mensagens estereotipadas, sinalizando as formas mais subtis de discriminação, mas que também envolvesse uma ética da informação dirigida à sociedade no seu conjunto que tomasse com seriedade em consideração as preocuções de igualdade de género e protecção de várias identidades ${ }^{28}$.

\section{Para uma perspectiva crítica das políticas para a igualdade de género nos media} Jupp (2006) apontou que a análise crítica das políticas envolve descobrir o que é tratado como conhecimento e analisar as consequências de tal conhecimento. Como resultado da nossa análise crítica, verificamos que:

- A questão das "mulheres nos media" é, em sua maioria, entendida como um problema de estereótipos. A maioria das medidas foca a questão das representações e os estereótipos são considerados o problema-chave. Trata-se de uma abordagem claramente insuficiente, seguindo uma consideração de Joke Hermes (2014 [2013]), uma vez que as questões de poder/acesso aos media estão maioritariamente ausentes. A integração da perspetiva de género nos meios de comunicação nunca é considerada.

- As questões relativas à publicidade estão, na sua maioria, ausentes e o foco é desproporcional no que diz respeito ao campo do jornalismo.

- As medidas propostas mantêm-se a um nível básico de "consciencialização". 20 anos depois do primeiro plano para a igualdade, destacam-se as declarações de boas intenções que não têm correspondência real com a situação real das mulheres nos media: seu acesso, seu poder de reverter imagens nocivas, os meios para identificar situações problemáticas e para as corrigir.

- Observa-se uma ausência de medidas concretas, como a criação de um observatório "género e meios de comunicação social" que possa fornecer um conhecimento sistemático das verdadeiras distorções de mulheres e homens nos meios de comunicação social. Isto foi sugerido pelo órgão regulador, ERC, mas até agora não foi materializado ${ }^{29}$. Certamente que o contexto cultural em que os media operam é

28 No âmbito da consulta pública de que foi objecto o V Plano, a ERC aprovou a deliberação 259/2013 em 5 de Outubro, que é portadora de uma perspectiva que em certos aspectos se encontra próxima á análise aqui realizada.

29 Entre 2010-2011, chegou a existir por iniciativa da sociedade civil, em concreto pela UMAR União das Mulheres Alternativa e Resposta, um Observatório das Representações de Género nos Media (https://sites.google.com/site/observatoriogeneromedia/), mas não teve continuidade. 
decisivo, mas o conhecimento da sua mudança só pode advir de indicadores e medidas concretas que traduzam esse conhecimento.

- Se no domínio das intenções parece existir sintonia entre as diversas instâncias envolvidas (internacionais, governo nacional e suas comissões e sociedade civil, organismos reguladores do sector), quando se passa para o domínio da execução das medidas propostas, a situação já não se revela tão favorável pelo menos no domínio da igualdade de género na área da comunicação e da informação.

- Não existe uma orientação global combinada entre as várias entidades públicas com responsabilidade no sector;

- Observa-se a ausência de uma estratégia global concertada ao nível do ensino, sector da comunicação social, etc.;

- Estas preocupações surgem nos planos nacionais para a igualdade de género, onde desde 2013, a ERC tem sido parceira (avaliação do IV plano e pronunciou-se sobre o V), mas não nas políticas públicas para o sector da comunicação social.

- Observa-se pouca ou nenhuma evolução de uns planos para os outros: os pontos fracos assinalados nos relatórios de avaliação dos planos não são, regra geral, decisivamente incorporados nos novos planos.

\section{NotAS CONCLUSIVAS E SUGESTIVAS}

Os resultados que apresentamos estão situados no quadro mais amplo de análise do impacto das políticas públicas sobre igualdade de género nos media e na comunicação que, no espaço europeu, é bastante recente. Só há pouco tempo, a Comissão incentivou um estudo alargado da Secção J da Plataforma de Pequim (EIGE, 2013; 2014; Ross e Padovani, 2017), centrado sobretudo na participação das mulheres na tomada de decisão nas empresas de media. Em Portugal, uma parte dessa investigação foi coordenada por Claudia Alvares e Iolanda Veríssimo que concluíram que "A distribuição de mulheres e homens em cargos de tomada de decisão das quatro organizações portuguesas analisadas é extremamente desigual" (Alvares e Veríssimo, 2017: 159), sendo o serviço público de radiodifusão aquele que apresenta maior sensibilidade para a questão da igualdade de género. Concluem ainda as autoras que "0 que agora é necessário é uma abordagem mais estratégica e bem planeada que seja efetivamente orientada para a integração da perspetiva de género e atenda às necessidades contextuais de formulação de políticas a nível nacional" (Alvares e Veríssimo, 2017: 168).

Isso mesmo é reforçado nas conclusões do estudo coordenado por Karen Ross e Claudia Padovani (2017), onde se destaca a necessidade de produzir indicadores mensuráveis sobre 0 mainstreaming de género nos meios de comunicação. Além desses indicadores, pensamos que é absolutamente necessária uma monitorização dos conteúdos dos media, como, aliás, é referido também no relatório sobre esta matéria apresentado pela Comissão de Igualdade de Género do Conselho da Europa em 2015 (CoE, 2015). Ora, os planos que analisámos não contêm nenhuma dessas vertentes e essa ausência de indicadores e meios de monitorização faz dos Planos instrumentos fracos de implementação dos impulsos democratizadores dos direitos das mulheres vindos de diferentes setores nacionais e europeus.

Na verdade, a nossa análise do lugar e do alcance das políticas de "género nos media" nos diversos planos nacionais e documentos associados mostra que exis- 
tem mecanismos que mimetizam iniciativas europeias, mas não as traduzem concretamente em medidas efectivas e consistentes que podem realmente afetar os objetivos de alcançar a igualdade de género nos media. Em geral, as medidas nesta área de preocupação, tal como estipuladas nos Planos de Igualdade analisados, são em grande parte simbólicas, sem o empenho dos recursos necessários e ações de execução. As frágeis medidas das "mulheres e dos meios de comunicação", como vimos, foram impulsionadas por processos de europeização mas, em termos de uma quadro de transferência de políticas são, pelo menos em parte, o resultado de uma adoção "superficial" de uma solução do exterior (Glick e Hays, 1991), com escassas possibilidades de eficácia. Mas o facto de a própria Comissão só recentemente ter produzido documentação sobre o sector dos media nas questões de Igualdade poderá também significar que mesmo a nível interestatal o problema ainda não tenha sido devidamente encarado.

Em jeito de notas sugestivas para futuros planos, consideramos, pois, importante, reforçar os processos de europeização a par da consolidação dos impulsos da própria sociedade civil nacional de modo a: detalhar e consolidar a área de preocupação em causa, especificando subáreas e conteúdos específicos que se constituem como críticos; dotar os futuros planos de indicadores concretos de evolução e de metas a atingir no caminho para a igualdade (ver Ross neste Número); desenvolver parcerias com as empresas dos media no sentido de criar ambientes culturais que reconheçam que a igualdade de género também é do seu próprio interesse, e ainda dotar os planos de igualdade de verdadeiros mecanismos de implementação dos seus objetivos (por exemplo, criando parcerias para a monitorização de conteúdos dos media).

Estes novos enfoques assumem que a importância dos Planos de lgualdade não é meramente simbólica: eles são expressões de compromisso político para com áreas prioritárias e, portanto, a sua própria conceção e implementação é chave para as consequentes ações políticas. Além disso, não devemos perder de vista que a sua eficácia depende de uma articulação adequada com medidas de "políticas duras", ou seja, o uso da legislação para forçar o cumprimento das metas desejadas. Isso significa repensar políticas mais amplas de media que não respondam apenas aos interesses das empresas, mas também às necessidades da democracia e de uma cidadania mais equitativa. No entanto, reconhecendo as dificuldades de realização desses objetivos face a interesses privados entrincheirados e enquanto a hostilidade neoliberal às políticas intervencionistas não for superada por imperativos quer de protecção social, quer de emancipação, o mínimo que os governos podem fazer é honrar seus compromissos políticos mais "suaves", através de medidas de implementação dos importantes impulsos democráticos de que deverão ser produtores e recetores.

\section{Bibliografia}

Alvares, C. e Verissimo, I. (2017). Portugal. Practice What you Preach: Deconstructing Gender Equality in Portuguese Media" In: Ross, K. e Padovani, C. ( ed.). Gender Equality and the Media. A Challenge for Europe. Nova lorque: Routledge.

Bustelo, M. e Peterson, E. (2005). The Evolution of Policy Discourses and Policy Instruments within the Spanish State Feminism. A Unified or Fragmented Landscape? Workshop: "State Feminism and Women"s Movements: Assessing Change of the Last Decade in 
Europe." ECPR Workshops. Granada, Spain. In (http://pendientedemigracion.ucm.es/ info/mageeq/documentos/Art_Evolution.pdf) (acedido em 15/01/2017).

Byerly, C. M. e Padovani, C. (2017). Research and Policy Review. In: Ross, K. e Padovani, C. (eds.). Gender Equality and the Media. Nova lorque: Routledge.

Cerqueira, C. e Cabecinhas, R. (2012). Políticas para a Igualdade entre Homens e Mulheres nos Media: da (Inov)ação Legislativa à Mudança Social", Ex Aequo 25:105-118.

Cerqueira, C. (2008). As Políticas da UNESCO para a Igualdade de Género nos Media 1977 -2007. In: Martins, M. L. (org.). Comunicação e Cidadania, Actas do V Congresso da SOPCOM, 6-8 de Setembro. Braga: Centro de Estudos de Comunicação e Sociedade, Universidade do Minho: 710-723.

CoE-Conselho da Europa (2015). Handbook on the implementation of Recommendation CM/ $\operatorname{Rec}(2013) 1$. Impresso no Concelho da Europa.

Comissão das Comunidades Europeias (2005). Comunicação da Comissão ao Conselho, ao Parlamento Europeu, ao Comité Económico e Social Europeu e ao Comité das Regiões, Combate à Discriminação e Igualdade de Oportunidades para Todos. Uma Estratégia-Quadro. Junho 2005.

Comissão das Comunidades Europeias (2006). Comunicação da Comissão ao Conselho, ao Parlamento Europeu, ao Comité Económico e Social Europeu e ao Comité das Regiões. Roteiro para a lgualdade entre Homens e Mulheres, Março, 2006.

Dolowitz, D. P. e Marsh, D. (1996). Who Learns what from Whom? A Review of the Policy Transfer Literature. Political Studies, 44 (2): 343-57.

EIGE - European Institute for Gender Equality (2013). Review of the Implementation of the Beijing Platform for Action in the EU Member States: Women and the Media: Advancing Gender Equality in Decision-Making in Media Organisations, Luxembourg: Publications Office of the European Union.

EIGE - European Institute for Gender Equality (2014). Interviews with Women Experts: What about Gender Equality in the Media? Luxembourg: Publications Office of the European Union.

Evans, M. (2009). Policy Transfer in Critical Perspective. Policy Studies 30(3): 243-268.

Ferreira, V. (2000). A Globalização das Políticas de Igualdade entre os Sexos: Do Reformismo Social ao Reformismo Estatal. Ex Aequo 2/3: 13-42.

Ferreira, V. (coord.); Portugal; S.; Silveirinha, M. J.; Vieira, C. Monteiro, R., Duarte, M. e Peça, M. (2007). Relatório Final para a CIG do Estudo de Avaliação do II Plano Nacional para a Igualdade, Coimbra: Centro de Estudos Sociais, Universidade de Coimbra.

Ferreira, V. (coord.); Silveirinha, M. J.; Portugal, S., Vieira, C.; Monteiro, R.; Duarte, M. e Lopes, M. (2011). Estudo de Avaliação do III Plano Nacional para a Igualdade - Cidadania e Género: Relatório Final para a CIG. Coimbra: APEU/FEUC. Disponível em http://www. ces.uc.pt/myces/UserFiles/livros/782_Estudo\%20de\%20Avalia\%E7\%E30\%20do\%20 III\%20PNI\%20-\%20Relat\%F3rio\%20Final\%202011-2.pdf . (acedido em 07/08/2016).

Ferreira, V. e Monteiro, R. (2013). Trabalho, Igualdade e Diálogo Social. Estratégias e desafios de um percurso. Lisboa: Comissão para a Igualdade no Trabalho e no Emprego. Freedman Des (2010). Media Policy Silences: The Hidden Face of Communications DecisionMaking. International Journal of Press/Politics 15 (3): 344-361. 
Freedman, Des (2008). The Politics of Media Policy. Cambridge, UK: Polity Press.

Gallagher, M. (2006). Perspectivas Feminista sobre os Media. Ex Aequo 14: 11-34.

Gallagher, M. (2011). Gender and Communication Policy: Struggling for Space. In: Mansell, R. e Raboy, M., The Handbook of Global Media and Communication Policy Blackwell Publishing: 451-466.

Glick, H. R., e Hays, S. P. (1991). "Innovation and Reinvention in State Policymaking: Theory and the Evolution of Living will Laws. The Journal of Politics 53: 835-850.

Hermes, J. (2014 [2013]). Mulheres e Jornalistas Primeiro. Um Desafio Lançado aos Profissionais dos Media para que Seja Possível Alcançar a Democracia na Prática, Criar um Jornalismo de Qualidade e Acabar com os Estereótipos de Género. Lisboa: CIG e Presidência do Conselho de Ministros.

Jupp, V. (2006). Documents and Critical Research. In: Sapsford, R. e Jupp, V. (eds.). Data Collection and Analysis. Londres: Sage: 272-290.

Lombardo, E. e Forest, M. (eds). (2012). The Europeanization of Gender Equality Policies. A Discursive-sociological Approach. Basingstoke: Palgrave MacMillan.

Magone, J. (2006). The Europeanization of Portugal (1986-2006). A Critical View. Nação e Defesa 115 (3): 9-28.

Marsh, D., e Sharman, J. C. (2009). Policy Diffusion and Policy Transfer. Policy Studies,30: 269-288.

Mazur, A. (2005). The Impact of Women's Participation and Leadership on Policy Outcomes: A Focus on Women's Policy Machineries. Expert Group Meeting on Equal participation of women and men in decision-making processes, with particular emphasis on political participation and leadership, Addis-Abeba, 24 a 27 Outubro http://www.un.org/womenwatch/daw/egm/eql-men/docs/EP.5_Mazur.pdf (acedido em 12/12/2016).

Monteiro, R. e Ferreira, V. (2012). Metamorfoses das Relações entre o Estado e os Movimentos de Mulheres em Portugal: entre a Institucionalização e a Autonomia. Ex Aequo 25: 13-27.

Monteiro, R. e Portugal, S. (2013). As Políticas de Conciliação nos Planos Nacionais para a Igualdade: Uma Análise de Quadros Interpretativos. Ex Aequo 27: 97-111.

Monteiro, R. (2011). Feminismo de Estado em Portugal: Mecanismos, Estratégias, Políticas e Metamorfoses. Doutoramento em Sociologia. Coimbra: Faculdade Economia, Universidade de Coimbra.

Rêgo, M. do C. da C, (2012). Politicas de Igualdade de Género na União Europeia e em Portugal. Influências e Incoerências. Aequo 25: 29-44.

Resolução do Conselho de Ministros nº 103/2013, publicada no Diário da República, I Série, $n^{0} 253,31$ Dezembro.

Resolução do Conselho de Ministros n 184/2003, publicada no Diário da República, I Série $B, n^{0} 273,23$ Novembro.

Resolução do Conselho de Ministros no 49/97, aprovada pelo Conselho de Ministros de 6 Março 1997e publicada no Diário da República, I Série B, nº 70, 24 Março.

Resolução do Conselho de Ministros nº 5/2011, publicada no Diário da República, I Série, $n^{0} 12,18$ Janeiro.

Resolução do Conselho de Ministros n 82/2007, publicada no Diário da República, I Série, n 119, 22 Junho. 
Ross, K. e Padovani, C. (eds). (2017). Gender Equality and the Media. A Challenge for Europe. Nova lorque: Routledge.

Sarikakis, K. e Nguyen, E. T. (2009). The Trouble with Gender: Media Policy and Gender Mainstreaming in the European Union". Journal of European Integration 31(2): 201-216.

Sarikakis, K. (2004). Powers in Media Policy: The Challenge of the European Parliament. Oxford: Peter Lang.

Sarikakis, K.e Ganter, S. (2014). Priorities in Global Media Policy Transfer: Audiovisual and Digital Policy Mutations in the EU, MERCOSUR and US Triangle". European Journal of Communication 29(1): 17-33.

Silva, M. R. T. da (s.d). História do CIG. Décadas de 70 a 90. Comissão para a Igualdade de Género. In: (www.cig.gov.pt/a-cig/historia-da-cig) (acedido 06/07/2015)

Silveirinha, M. J. (2012). Repensar as Políticas Públicas sobre as Mulheres e os Media ou do quão Cruciais são os Estudos Feministas da Comunicação. Ex Aequo 25: 91-104.

Stone, D. (2004). Transfer Agents and Global Networks in the "Transnationalization" of Policy. Journal of European Public Policy 11 (3): 545-66.

Torres, A., Costa, D., Sant'ana H., Pinto, P. e Coelho, B. (2013) Estudo de Avaliação do IV Plano Nacional para a lgualdade, Género, Cidadania e Não Discriminação (2011-2013). Lisboa: Instituto Superior de Ciências Sociais e Políticas, Universidade de Lisboa.

UNESCO (1981 [1980]). Many voices. One World. Report by the Internacional Commission for the Study of Communication Problems, Londres, Nova lorque, Paris: Kogan Page/ Unipub e UNESCO.

Filipa Subtil - é doutorada em Ciências Sociais pelo Instituto de Ciências Sociais da Universidade de Lisboa e docente na Escola Superior de Comunicação Social, IPL. Os seus interesses de investigação têm-se centrado na Sociologia da Comunicação, na teoria social dos media nos EUA e Canadá e nas problemáticas que relacionam os media com as questões de género, áreas onde tem publicado.

Maria João Silveirinha - é doutorada pela Universidade Nova de Lisboa e é Professora Associada na Faculdade de Letras da Universidade de Coimbra. Tem participado e liderado diversos projetos sobre a temática género e media e integra o CIC. Digital, onde investiga esta área científica.

Artigo por convite /Article by invitation 